\title{
Cooperation or Non-Cooperation: A Bargaining Game Model to Make Dominant Coalition
}

\author{
Zagross Hadadian ${ }^{1}$, Sanaz Malekpour ${ }^{2}$
}

\begin{abstract}
The concept of coalition is central to classic and recent organizational theory. This paper focuses on study of organizational coalition by using Bargaining Game Model. Players in the model are carrying on an intensive competition to maximize their utility. We study the game between two players based on Nash Bargaining game theory. We propose a game theoretical framework that shows how the players of the game determine the optimal strategy to cooperate or not cooperate in a coalition. Moreover, the influences of cooperation costs and betrayal incomes in the cooperation strategies between players are analyzed. The result shows that the cooperation of players has a negative relation with the cooperation costs and betrayal income; with the increase of cooperation costs and betrayal income, the players will become reluctant to cooperate.
\end{abstract}

\section{Keywords: Dominant coalition, Game theory}

\section{Introduction}

The concept of a dominant coalition can be found in the works of organizational theorists (Grunig, 1992). This group of influential are also called as inner circle (Thompson,1967).According to Cyert and March (1963) a coalition of individuals set organizational goals, and the values of this group shape organizational behaviors.

Power holders compete to make influence on organizational decisions and resource allocations and these ongoing conflicts yield organizational structure (Lauzen \& Dozier, 1992). Power-control viewpoint in organizations (Child, 1972; Pfeffer, 1981; Simon, 1976) claims that some Members draw power from a range of sources-authority, coercion, charisma, expertise, information, reward, and sanctions in order to make influence on decisions (Bachrach \& Lawler, 1980; French \& Raven, 1959). These members make dominant coalition.

A Social Psychologist, Karl Weick (1969) explained a system of coalitions that forms power for two people to make a decision for an entire group. In this system, two people meet each other and decide to vote for a subject. They accept another member and decide that they will vote the same in the large group by majority rule (Murnighan, 1985). In organizational studies, there is an assumption that organizational members are reasonably aware of their own interests and they attempt to maximize their utility whenever possible. These assumptions fit nicely with the basic assumptions of most 
coalition theories, that people are informed and attempt to maximize their outcomes (Murnighan, 1985).In this study we assume the same.

Coalition theories, with few exceptions are static models (Murnighan, 1985). There are some instability among the coalitions, but the coalition situation such as rules and structures may not change (Murnighan, 1985). Dominant coalitions are formed to preserve or increase the resources of the coalition's members. According to social psychologists doing research on coalition behavior, resources can be defined as votes (Gamson, 1961; Vinacke and Arkoff, 1957). Holding more resources upsurges the possibility that a member will be included in a winning coalition. Moreover, governing of unique resources increase the flexibility and bargaining forte of a member (Komorita, 1977). If a member holds more resources than others do, s/he becomes a critical coalition member and in some cases no coalition will be effective without the inclusion of this individual (Murnighan, 1985). This notion of criticality (Murnighan and Vollrath, 1985) can be referred to pivotal in a coalition (Shapley and Shubik, 1954). Critical, central, pivotal organizational members are those who should necessarily agree with a decision before it can be implemented (Murnighan, 1985).

One who deals from strength often does not need to make the first move; instead, the one who cannot reach what s/he desires without a coalition, must initiate action. By initiating a coalition bargaining, one indicates that his dependence on the potential alliance is at least greater than his potential partner's dependence (Murnighan, 1985). One who is interested in negotiation for collaboration sacrifices some strength unless $\mathrm{s} /$ he has significant information about the costs that a potential partner would face if s/he did not joint this coalition (Yukl, 1974). These Sacrifices of strength can be considered as the cost of collaboration for members.

From game theoretic point of view, the payoffs of any pair of bargainers can be studied. Researchers such as (Nydegger and Owen, 1975; Roth and Malouf, 1978; Roth, Malouf, and Murnighan, 1981; Roth and Murnighan, 1982) claim that when the bargainers have no information about each other's actual payoffs, the payoffs can be equalized by 50-50 splits. Siegel and Fouraker (1960) also indicated that, when one bargainer has exceedingly high aspirations, s/he bargained more strongly and obtained more from the negotiations.

There are different models such as Komorita's models of coalition behavior, the Weighted Probability Model (Komorita, 1974), and Equal Excess Theory (Komorita, 1979) that focus directly on the coalition behaviors, But according to (Kravitz, 1981; Murnighan, 1978), Bargaining Theory (Komorita and Chertkoff, 1973) can be a better predictor of coalition behavior.

\section{Game theory}

There are a number of definitions for game theory. For instance, Myerson (1997) defines it as a mathematical modeling of interactions among decision makers. Gibbons(1992) describes game theory as an examination of multi-person decision problems and Osborne and Rubinstein (1994), in their investigation into game theory, underline that game theory is a batch of analytical tools used to understand a phenomena 
caused by decision makers interaction. Based on these definitions, we decide to use game theory in our paper.

This paper discusses a Bargaining Game Model to make dominant coalition. The organization of rest of the paper is as follows: elements of the proposed model and the benefit matrix are presented in Model part. Bargaining game part briefly discusses the Bargaining game and its application. In Breakdown point section, breakdown point is introduced and the algorithm of game procedure is presented. Finally, in Numerical example, a numerical example is presented and in Numerical example analysis, results are analyzed. Eventually, concluding remarks and suggestions for the future research are given in Conclusion section.

\section{Model}

This paper studies the relationship between two players to make a dominant coalition. They both have two options: cooperation or non-cooperation with the other player. Each selected strategy has different levels of profit for each player. To establish the model, following indexes, parameters and variables are used:

$\pi_{1}$ : The normal income of player 1 , when both players choose non-cooperation.

$\pi_{2}$ :The normal income of player2, when both players choose non-cooperation.

$\Delta \pi$ :The excess income they obtain when they successfully cooperate.

$\Delta \pi^{\prime}{ }_{1}:$ The incremental income that the player1 obtains when he wants to cooperate and the player2 doesn't cooperate.

$\Delta \pi^{\prime}{ }_{2}:$ The incremental income that the player2 obtains when he wants to cooperate and the player1 doesn't cooperate.

$\beta$ :The proportion of excess income allocation for Player 1; then Player 2's is 1- $\beta$.

$\mathrm{C}_{1}$ : The cost that player1 has to undertake when two players cooperate.

$\mathrm{C}_{2}$ : The cost that player2 has to undertake when two players cooperate.

$\mathrm{E}_{1}$ : The betrayal income that player1 obtains from the gentle strategy player2 adopts.

E2: The betrayal income that player2 obtains from the gentle strategy player1 adopts.

The profit function for the Player1 is as follows:

$\Pi_{1}=\pi_{1}+k_{1}\left(\beta \Delta \pi-C_{1}\right)+u_{1}\left(\Delta \pi^{\prime}{ }^{\prime}-C_{1}\right)+\nu_{1}\left(E_{1}\right)$

Where $k_{1}, u_{1}, v_{1}$ and $k_{1}+u_{1}+v_{1} \in\{0,1\}$. If both parties choose to cooperate, $k_{1}=1, u_{1}=$ $v_{1}=0$, If the Player1 wants to cooperate but Player 2 does not want, $u_{1}=1, k_{1}=v_{1}=0$. When Player1 is not willing to cooperate and the Player2 is willing, $v_{1}=1, k_{1}=u_{1}=0$. If both players are not willing to cooperate, $v_{1}=0, k_{1}=u_{1}=0$.

Similarly, the profit function for Player 2 is as follows:

$\Pi_{2}=\pi_{2}+k_{2}\left((1-\beta) \Delta \pi-C_{2}\right)+u_{2}\left(\Delta \pi^{\prime}{ }^{-} C_{2}\right)+v_{2}\left(E_{2}\right)$

The profit functions (1) and (2), show that each players' profit has a positive relation with incomes and a negative relation with cooperation costs.

Therefore, the benefit matrix of the game between Player1 and Player2, pertaining to various combinations of strategies of Player1 and Player2, is presented in Table 1. 
Table1.The benefit matrix of the game between player 1 and player2

\begin{tabular}{|l|l|l|l|}
\hline \multicolumn{2}{|c|}{} & \multicolumn{2}{|l|}{ Player 2 } \\
\cline { 3 - 4 } \multicolumn{2}{|c|}{} & Cooperation & None-Cooperation \\
\hline \multirow{3}{*}{ Player1 } & Cooperation & $(\mathrm{A}, \mathrm{B})$ & $(\mathrm{C}, \mathrm{D})$ \\
\cline { 3 - 4 } & Non-cooperation & $(\mathrm{E}, \mathrm{F})$ & $(\mathrm{G}, \mathrm{H})$ \\
\hline
\end{tabular}

Where,

$$
\begin{aligned}
& \mathrm{A}=\pi_{1}+\beta \Delta \pi-C_{1} \\
& \mathrm{~B}=\pi_{2}+(1-\beta) \Delta \pi-C_{2} \\
& \mathrm{C}=\pi_{1}+\Delta \pi^{\prime}{ }_{1}-C_{1} \\
& \mathrm{D}=\pi_{2}+\mathrm{E}_{2} \\
& \mathrm{E}=\pi_{1}+\mathrm{E}_{1} \\
& \mathrm{~F}=\pi_{2}+\Delta \pi^{\prime}{ }^{2} C_{2} \\
& \mathrm{G}=\pi_{1} \\
& \mathrm{H}=\pi_{2}
\end{aligned}
$$

\section{Bargaining Game}

The goal of the Nash Bargaining game, as a cooperative game, is dividing the benefits or utility between two players based on their competition. The Nash bargaining game model (Nash, 1950) requires the feasible set to be compact and convex. It contains some payoff vectors, so that each individual payoff is greater than the individual breakdown payoff. Breakdown Payoffs or Breakdown points are the starting point for bargaining which represent the possible payoff pairs obtained if one player decides not to bargain with the other player.

If $\vec{u}$ and $\vec{b}$ are the payment (benefit) and breakdown payoffs vector for the individuals respectively, so we must maximize $\prod_{i=1}^{2}(u i-b i)$ by solving the following maximization problem:

$\operatorname{Max}\left(u_{1}-b_{1}\right)\left(u_{2}-b_{2}\right)$

St: $u_{1}>=b_{1}$

$$
u_{2}>=b_{2}
$$

Where $\left(u_{1}, u_{2}\right) \in\{(\mathrm{A}, \mathrm{B}),(\mathrm{C}, \mathrm{D}),(\mathrm{E}, \mathrm{F}),(\mathrm{G}, \mathrm{H})\}$

\section{Breakdown Points}

The choice of the breakdown point is a matter of modeling judgment (Binmore et al., 1986). In the benefit matrix, presented in (Table.1), let

$$
\theta^{1} \min =\min \{A, C, E, G\} \text { and } \theta^{2} \min =\min \{B, D, F, H\}
$$

Therefore, $\theta^{1} \mathrm{~min}$ and $\theta^{2} \mathrm{~min}$ are the worst achievable benefit for Player1 and player2, respectively. Therefore, we use $\theta^{1} \mathrm{~min}$ and $\theta^{2} \mathrm{~min}$ as breakdown point. The algorithm of the game procedure is as follows: 
According to the data of Player1and Player2, first, the benefit matrix is calculated and then the optimal strategies for this game are obtained from the Nash bargaining problem.

\section{Numerical example}

In this section, we provide the numerical examples to discuss how the theoretical results in this paper can practically be applied. It is supposed that both player1 and Player2 have two options: cooperation or non-cooperation with the other Player. We consider 30 different examples to demonstrate the effect of cooperation costs, $C 1$ and $C 2$, and betrayal incomes, E1 and E2, on the equilibrium. These examples are distinctive according to the cooperation costs and betrayal incomes for each Player. Data for this numerical example is presented in Table 2. Moreover, the benefit matrix for the game between the Player1 and Player2, in this example, is shown in Table 3.

Table2.Data for numerical example

\begin{tabular}{|l|l|l|l|}
\hline Variable & 850 & $\beta$ & 0.7 \\
\hline$\pi 1$ & 650 & $\Delta \pi^{\prime}{ }_{1}$ & 100 \\
\hline$\pi 2$ & 200 & $\Delta \pi^{\prime}{ }_{2}$ & 80 \\
\hline$\Delta \pi$ & &
\end{tabular}

Table3.The benefit matrix of the game between player 1 and player2

\begin{tabular}{|c|c|c|c|}
\hline & \multicolumn{2}{|l|}{ Player 2} \\
\hline & & Cooperation & None-Cooperation \\
\hline \multirow[t]{2}{*}{ Player1 } & Cooperation & $\begin{array}{l}(850+0.7 * 200- \\
\mathrm{C} 1,650+0.3 * 200-\mathrm{C} 2)\end{array}$ & $(850+100-\mathrm{C} 1,650+\mathrm{E} 2)$ \\
\hline & Non-cooperation & $(850+\mathrm{E} 1,650+80-\mathrm{C} 2)$ & $(850,650)$ \\
\hline
\end{tabular}

First, for 10 different levels of $(\mathrm{E} 1, \mathrm{E} 2)$, when $(\mathrm{C} 1, \mathrm{C} 2)=(30,30)$, then by considering $(\mathrm{E} 1, \mathrm{E} 2)=(50,40)$, for different levels of $(\mathrm{C} 1, \mathrm{C} 2)$, the model is solved and the results are summarized in the Table 4 and the Table 5.

Table4. Numerical results for 10 different levels of $(\mathrm{E} 1, \mathrm{E} 2)$ when $(\mathrm{C} 1, \mathrm{C} 2)=(30,30)$

\begin{tabular}{|l|l|l|l|l|l|}
\hline$(\mathrm{E} 1, \mathrm{E} 2)$ & $\begin{array}{l}\left(\theta^{1} \mathrm{~min},\right. \\
\left.\theta^{2} \min \right)\end{array}$ & $\begin{array}{l}\text { Equilibrium } \\
\text { strategy }\end{array}$ & $(\mathrm{E} 1, \mathrm{E} 2)$ & $\begin{array}{l}\left(\theta^{1} \min \right. \\
\left.\theta^{2} \min \right)\end{array}$ & $\begin{array}{l}\text { Equilibrium } \\
\text { strategy }\end{array}$ \\
\hline$(30,30)$ & $(850,650)$ & $(\mathrm{A}, \mathrm{B})$ & $(60,60)$ & $(850,650)$ & $(\mathrm{A}, \mathrm{B})$ \\
\hline$(30,80)$ & $(850,650)$ & $(\mathrm{A}, \mathrm{B})$ & $(60,130)$ & $(850,650)$ & $(\mathrm{A}, \mathrm{B})$ \\
\hline$(30,130)$ & $(850,650)$ & $(\mathrm{C}, \mathrm{D})$ & $(60,170)$ & $(850,650)$ & $(\mathrm{C}, \mathrm{D})$ \\
\hline$(80,30)$ & $(850,650)$ & $(\mathrm{E}, \mathrm{F})$ & $(130,60)$ & $(850,650)$ & $(\mathrm{E}, \mathrm{F})$ \\
\hline$(130,30)$ & $(850,650)$ & $(\mathrm{E}, \mathrm{F})$ & $(170,60)$ & $(850,650)$ & $(\mathrm{E}, \mathrm{F})$ \\
\hline
\end{tabular}


Table5. Numerical results for 20 different levels of $(\mathrm{C} 1, \mathrm{C} 2)$ when $(\mathrm{E} 1, \mathrm{E} 2)=(50,40)$

\begin{tabular}{|l|l|l|l|l|l|}
\hline$(\mathrm{C} 1, \mathrm{C} 2)$ & $\begin{array}{l}\left(\theta^{1} \mathrm{~min}\right. \\
\left.\theta^{2} \mathrm{~min}\right)\end{array}$ & $\begin{array}{l}\text { Equilibruim } \\
\text { strategy }\end{array}$ & $(\mathrm{C} 1, \mathrm{C} 2)$ & $\begin{array}{l}\left(\theta^{1} \mathrm{~min},\right. \\
\left.\theta^{2} \mathrm{~min}\right)\end{array}$ & $\begin{array}{l}\text { Equilibruim } \\
\text { strategy }\end{array}$ \\
\hline$(30,30)$ & $(850,650)$ & $(\mathrm{A}, \mathrm{B})$ & $(80,80)$ & $(850,630)$ & $(\mathrm{C}, \mathrm{D})$ \\
\hline$(30,80)$ & $(850,650)$ & $(\mathrm{C}, \mathrm{D})$ & $(80,100)$ & $(850,610)$ & $(\mathrm{C}, \mathrm{D})$ \\
\hline$(30,100)$ & $(850,610)$ & $(\mathrm{C}, \mathrm{D})$ & $(80,120)$ & $(850,630)$ & $(\mathrm{C}, \mathrm{D})$ \\
\hline$(30,120)$ & $(850,590)$ & $(\mathrm{C}, \mathrm{D})$ & $(80,140)$ & $(850,570)$ & $(\mathrm{C}, \mathrm{D})$ \\
\hline$(30,140)$ & $(850,570)$ & $(\mathrm{C}, \mathrm{D})$ & $(100,80)$ & $(850,630)$ & $(\mathrm{E}, \mathrm{F})$ \\
\hline$(50,30)$ & $(850,650)$ & $(\mathrm{A}, \mathrm{B})$ & $(120,80)$ & $(850,630)$ & $(\mathrm{E}, \mathrm{F})$ \\
\hline$(80,30)$ & $(850,650)$ & $(\mathrm{E}, \mathrm{F})$ & $(140,80)$ & $(810,630$ & $(\mathrm{E}, \mathrm{F})$ \\
\hline$(100,30)$ & $(850,650)$ & $(\mathrm{E}, \mathrm{F})$ & $(200,200)$ & $(750,510)$ & $(\mathrm{G}, \mathrm{H})$ \\
\hline$(120,30)$ & $(810,650)$ & $(\mathrm{E}, \mathrm{F})$ & $(0,20)$ & $(850,650)$ & $(A, \mathrm{~B})$ \\
\hline
\end{tabular}

\section{Numerical example analysis}

In the numerical example, the Nash equilibrium strategy is calculated for 30 different levels of $(C 1, C 2, E 1, E 2)$. When $(C 1, C 2)$ were constant, the results show that the equilibrium strategies were totally depended on $(E 1, E 2)$. In the high betrayal income for Player1, for example, E1 $\square 130$, Player1 is not willing to cooperate and in the high betrayal income for Player2, for example E2 $\square 170$, the Player2 is not willing to cooperate. In addition, the results show that, in the constant $(E 1, E 2)$, the equilibrium strategies for Player1 and Player2 entirely depend on $(C 1, C 2)$. Keeping $C 1$ constant, with the increase of $C 2$, the Player2 does not want to cooperate. Similarly, with the constant $C 2$ and the increase of $C 1$, Player 1 hesitates to cooperate. When $(C 1, C 2)=$ $(30,140)$ or $(80,140)$, in the high amounts of $C 2$, the equilibrium strategy is $(C, D)$, the non-cooperative strategy for Player2. When $(C 1, C 2)=(120,30)$ or $(140,80)$, in the high amounts of $\mathrm{C1}$, the non-cooperation strategy is the equilibrium strategy for the Player1, (E, F). When both of (C1, C2) have high amounts, for example $(200,200)$, both Players become reluctant to cooperate and the equilibrium strategy is $(\mathrm{G}, \mathrm{H})$.

\section{Conclusion}

To answer the question "cooperation or non-cooperation?" in dominant coalitions, a bargaining game between two players is studied. The proposed framework clarifies how members of any organizations choose optimal strategies in participating any coalition. The frame shows the way members of organization choose the optimal strategy regarding their costs and profits in each possible strategy. A numerical example illustrates the model's performance in 30 different levels of the cooperation costs and the betrayal incomes. The results show that the equilibrium strategies entirely depend on the cooperation costs and the betrayal incomes. With the increase of costs, the players will become reluctant to cooperate. Moreover, in the constant cooperation costs, with the increase of betrayal incomes, the players do not show interest for cooperation. There are several directions and suggestions for future research. For instance, the proposed model can be studied with more than two Players. Moreover, it would be interesting to consider the uncertainty on model parameters such as cooperation costs or benefits of players. 


\section{References}

Bachrach, S., \& Lawler, E. (1980). Power and politics in organizations. San Francisco: Jossey-Bass.

Binmore, K., Rubinstein, A., \& Wolinsky, A. (1986). The Nash bargaining solution in economic modelling. The RAND Journal of Economics, 176-188.

Child, J. (1972). Organizational structure, environment, and performance: The role of strategic choice. Sociology, 6(1), 2-22.

Cyert, R. M., \& March, J. G. (1963). A behavioral theory of the firm. Englewood Cliffs, NJ: PrenticeHall.Lauzen, M. M., \&Dozier, D. M. (1992). The missing link: The public relations manager role as mediator of organizational environments and power consequences for the function. Journal of Public Relations Research, 4, 205-220.

French, J. R. P.,\&Raven, B. (1959). The bases of social power. In D. Cartwright (Ed.), Studies in social power (pp. 150-167). Ann Arbor: University of Michigan Institute for Social Research.

Gamson, W. A. (1961) "A theory of coalition formation." American Sociological Review, 26, 565-573.

Gibbons, R. 1992. Game theory for applied economists, Princeton University Press.

Grunig, J. (1992). Excellence in public relations and communication management. Mahwah, NJ: Lawrence Erlbaum Associates, Inc.

Komorita, S. S. and Chertkoff, J. M. (1973) "A bargaining theory of coalition formation," Psychological Review, 80, 149-162.

Komorita, S. S. (1974) "A weighted probability model of coalition formation" - Psychological Review , 81, 242-256.

Komorita, S. S. (1979) "An equal excess model of coalition formation," Behavioral Science, 24, 369-381.

Komorita, S. S. (1977) "The concept of bargaining strength," Journal of Theoretical Social Behavior, 16, 199217.

Kravitz, D. D. (1981) "Effects of resources and alternatives on coalition formation," Journal of Personality and Social Psychology, 4, 87-89.

Murnighan, J. K. (1978) "Stength and weakness in four coalition situations," Behavioral Science, 23, 195-208.

Murnighan, J. K. (1981) "Defectors, vulnerability and relative power: Some causes and effects of leaving a stable coalition," Human Relations, 34, 580-609.

Murnighan, J. K. and Vollrath, D. A. (1985) "Hierarchies, coalitions, and organizations." In S. B. Bacharach and E. J. Lawler (Eds), Perspectives in Organizational Sociology, Greenwich, Conn.: JAI Press.

Murnighan, J. K. (1985). Organizational coalition formation: process, consequences and dominant coalitions. BEBR faculty working paper; no. 1119.

Myerson, R. B. 1997. Game Theory: Analysis of Conflict, Harvard University.

Nash Jr, J. F. (1950). The bargaining problem. Econometrica: Journal of the Econometric Society, 155-162.

Nydegger, R. and Owen, G. (1975) "Two person bargaining: An experimental test of the Nash axioms." International Journal of Game Theory, 3_, 239-249.

Osborne, M. J. \& Rubinstein, A. 1994. A course in game theory, MIT press.

Pfeffer, J. (1981) Power in organizations. Marshfield, MA: Pitnam.

Plowman, K. D. (1998). Power in conflict for public relations. Journal of Public Relations Research, 10, 237 261.

Roth, A. E. and Murnighan, J. K. (1982) "The role of information in bargaining: An experimental study," Econometrica , 50, 1123-1142.

Shapley, L. and Shubik, M. (1954) "The power of a committee." American Political Science Review.

Siegel, S. and Fouraker, L. E. (1960) Bargaining and group decision-making, New York: McGraw Hill.

Simon, H. A. (1976). Administrative behavior (3rd ed.). New York: Free Press.

Thompson, J. D. (1967). Organizations in action. New York: McGraw-Hill.

Vinacke, W. E. and Arkoff, A. (1957) "An experimental study of coalitions in the traid," American Sociological Review, 22, 406-414.

Weick, K. (1969) The Social Psychology of Organizing, Appleton, Wis.: Addison-Wesley

Yukl, G. A. (1974) "Effects of situational variables and opponent concessions on a bargainer's perception, aspirations, and concessions," Journal of Personality and Social Psychology, 29,227-236. 
